\title{
Synthesis and Properties of Aromatic Polyamides and Polyimides from 9,10-Dihydro-9,10-o-benzenoanthracene-1,4-diamine
}

\author{
Yoshio Kasashima, Takuya Kaneda, ${ }^{*}$ Fumihiko Axutsu, ${ }^{*}, \dagger$ \\ Kiyoshi Naruchi,* and Masatoshi MiURA* \\ Graduate School of Science and Technology, Chiba University, \\ Yayoi-cho 1-33, Inage-ku, Chiba-shi 263, Japan \\ * Chiba University, Department of Applied Chemistry, Faculty of Engineering, \\ Yayoi-cho I-33, Inage-ku, Chiba-shi 263, Japan
}

(Received April 5, 1994)

\begin{abstract}
Aromatic polyamides and polyimides were synthesized from 9,10-dihydro-9,10$o$-benzenoanthracene-1,4-diamine (2,5-triptycenediamine). Aromatic polyamides were synthesized by the low-temperature solution polycondensation, whose inherent viscosities were $0.67-1.68$ $\mathrm{dl}^{-1}$. The polyamide from isophthaloyl dichloride was soluble in dimethylacetamide (DMAc), 1-methyl-2-pyrrolidone (NMP), dimethylformamide (DMF), dimethylsulfoxide (DMSO), and conc. sulfuric acid. The solubility was lower than that of corresponding polyamides from 2,7triptycenediamine. This lowering was attributed to the more linear and symmetrical structure of the diamine component. The glass transition temperatures $\left(T_{\mathrm{g}} \mathrm{s}\right)$ of the polyamides were 339$370^{\circ} \mathrm{C}$ and temperatures at $5 \%$ weight loss $\left(T_{\mathrm{d}}\right)$ were $442-482^{\circ} \mathrm{C}$, which indicate that this polyamide has high thermal stability. These thermal properties were as high as those of polyamide from 2,7-triptycenediamine. The aromatic polyimides were synthesized by thermal cyclodehydration from polyamic acids prepared from the diamine with tetracarboxylic dianhydride by ring-opening polyaddition. The inherent viscosities of the polyamic acids were $0.65-0.87 \mathrm{dlg}^{-1}$. Polyimide from the diamine with 3,3'4,4'-sulfonyldiphenyltetracarboxylic dianhydride was soluble in DMAc, DMF, DMSO, and conc. sulfuric acid. $T_{\mathrm{g}} \mathrm{s}$ of polyimides were $391-411^{\circ} \mathrm{C}$ and $T_{\mathrm{d}} \mathrm{s}$ were up to $521^{\circ} \mathrm{C}$, which were showed high values.
\end{abstract}

KEY WORDS 9,10-Dihydro-9,10-o-benzenoanthracene-1,4-diamine / Aromatic Polyamide / Aromatic Polyimide / Solubility / Thermal Property /

Aromatic polyamides and polyimides are well known as thermal resistant materials. But, their rigid structures cause high softening temperature and poor solubility to many organic solvents, and thus they are costly and difficult to apply to industry. ${ }^{1}$ Therefore, investigations concerned with the improvement of solubility have proceeded extensively. We regard the introduction of the rigid and three-dimensionally bulky triptycene structure to polyamide backbone as the effectiveness in the improvement of solubility and report$\mathrm{ed}^{2}$ preparations and properties of aromatic polyamides from 9,10-dihydro-9,10-o-benzenoanthracene-1,5-diamine (2,7-triptycene- diamine) 1 having high thermal properties and good solubility. In this report, the syntheses and properties of polyamides and polyimides from 9,10-dihydro-9,10-o-benzenoanthracene-1,5-diamine (2,5-triptycenediamine) 3 are investigated. The structure of polyamide backbone introduced 2,5-triptycenediyl unit is more linear and symmetrical than those introduced 2,7-triptycenediyl unit. Accordingly, it is considered that these factors influence the properties of polyamides. It is interesting and important to clear these influence from the view point of the design of new aromatic polyamides having good solubility and thermal properties. Mikitaev et al. 
already reported ${ }^{3}$ polyamides, polyimides, and polymeric Schiff base from 2,5-triptycenediamine. However, their inherent viscosities were not very high $\left(0.40-0.50 \mathrm{dl} \mathrm{g}^{-1}\right)$. In addition, concerning thermal properties, only the temperature at $10 \%$ weight loss was reported, and other thermal properties such as glass transition temperature were not investigated. Moreover, the solubility of polymers to organic solvents was not examined. It is impossible to discuss the relation between the modification of polyamide structure and characterization by the comparison of the report ${ }^{3}$ of Mikitaev et al. with our study. Therefore, we synthesized polyamides and polyimides polycondensated diamine 3 with several aromatic dicarbonyl dichlorides or tetracarboxylic dianhydride having higher inherent viscosities, and examined thermal properties as well as the solubility in many organic solvents of those polymers obtained.

\section{RESULTS AND DISCUSSION}

9,10-Dihydro-9,10-o-benzenoanthracene1,4-diamine 3 (2,5-triptycenediamine) was prepared by the method ${ }^{4}$ of Barttlett et al. from anthracene. Total yield from the starting material was $27.4 \%$.

Model reactions for polyamide and poly- imide syntheses were performed by the use of benzoyl chloride or phthalic anhydride. The structures of obtained products were confirmed by spectroscopic data as well as by elemental analysis. IR spectra of model compounds showed characteristic amide or imide adsorptions.

Poly(imino-9,10-dihydro-9,10-o-benzenoanthracene-1,4-diyliminocarbonylarylenecarbonyl)s (4a-d) were prepared by the lowtemperature solution polycondensation ${ }^{5}$ of diamine 3 with aromatic dicarbonyl dichlorides, e.g., terephthaloyl dichloride (a), isophthaloyl dichloride (b), 4,4'-biphenyldicarbonyl dichloride (c), 4,4'-sulfonyldibenzoyl dichloride (d). Lithium carbonate or propylene oxide was used as hydrogen chloride acceptor. The results are shown in Table I. All polycondensations proceeded in quantitative yields. The IR spectra of the polymers showed characteristic amide absorptions near 1660 and $1510 \mathrm{~cm}^{-1}$. The inherent viscosities of polyamides synthesized by propylene oxide were higher than those by lithium carbonate.

Solubility in several organic solvents is indicated in Table II. Polyamide $4 \mathbf{a}$ and $\mathbf{4 c}$ were soluble in conc. sulfuric acid only. But polyamide $4 \mathbf{b}$ was soluble in dimethylsulfoxide (DMSO), dimethylformamide (DMF), 1-methyl-2-pyrrolidone (NMP), dimethylacetamide
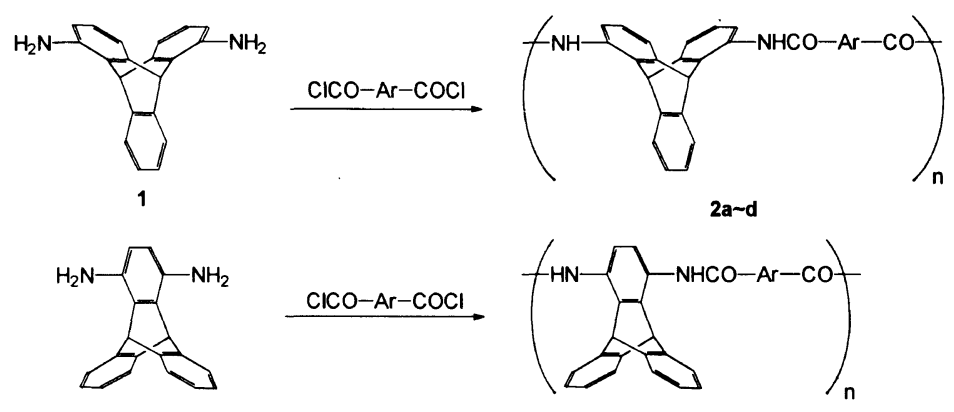

3
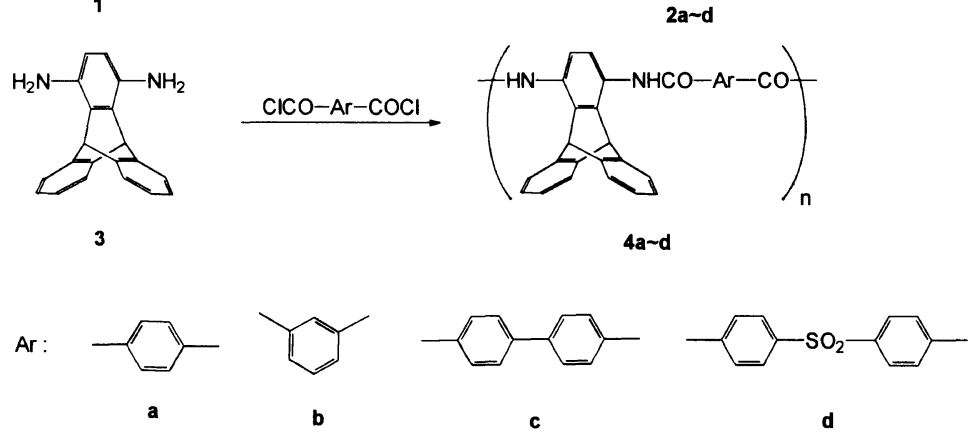
(DMAc), and pyridine. Polyamide 4d was soluble in hexamethylphosphoric triamide (HMPA) in addition to these solvents except pyridine. Compared with the solubility of polyamides 2 , that of polyamides 4 was lower. In particular, while polyamide 2 a was soluble in many organic solvents, corresponding polyamide 4a was slightly soluble. Polyamide 4b was not soluble in $m$-cresol and cyclohex-

Table I. Results of prepation of polyamides

\begin{tabular}{|c|c|c|c|c|c|}
\hline \multirow{2}{*}{ Polymer } & \multirow[t]{2}{*}{ Method $^{\mathrm{a}}$} & Yield & $\eta_{\mathrm{inh}}^{\mathbf{b}}$ & \multirow{2}{*}{ Appearance } & \multirow{2}{*}{ Color } \\
\hline & & $(\%)$ & $\mathrm{dl} \mathrm{g}^{-1}$ & & \\
\hline \multirow{2}{*}{$4 \mathbf{a}$} & PO & 97.0 & 0.67 & $S$ & White \\
\hline & $\mathrm{LC}$ & 101.1 & 0.44 & $S$ & White \\
\hline \multirow{2}{*}{$4 b$} & PO & 101.2 & 1.00 & $\mathbf{S}$ & Pale yellow \\
\hline & LC & 101.0 & 0.48 & $\mathbf{P}$ & Pale yellow \\
\hline \multirow{2}{*}{$4 c$} & PO & 99.9 & 1.68 & $\mathbf{P}$ & Pale yellow \\
\hline & $\mathrm{LC}$ & 102.1 & 0.97 & $\mathbf{P}$ & Pale yellow \\
\hline \multirow{2}{*}{ 4d } & PO & 96.5 & 0.84 & $S$ & White \\
\hline & $\mathrm{LC}$ & 96.3 & 0.69 & S & White \\
\hline
\end{tabular}

a PO, low-temperature solution polycondensation used propylene oxide as acid acceptor; LC, low-temprature solution polycondensation used lithium carbonate as acid acceptor.

b Measured at a concentration of $0.50 \%$ in conc. $\mathrm{H}_{2} \mathrm{SO}_{4}$ at $30^{\circ} \mathrm{C}$.

c S, homogeneous system; P, heterogenous system. anone in which polyamide $\mathbf{2 b}$ was soluble on heating. Polyamide 4d was also partially soluble in DMF and pyridine in which polyamide 2d was soluble at room temperature. This tendency was attributed to the shape and degree of the symmetry of the polyamide backbone. The structure of 2,7-triptycenediyl unit is more asymmetrical than that of 2,5triptycenediyl unit, while both are rigid.

Thermal properties of polyamides 4 are shown in Table III. The glass transition temperatures $\left(T_{\mathrm{g}} \mathrm{s}\right)$ of polyamides $4 \mathbf{a}$ and $4 \mathbf{c}$ were not observed by differential scanning calorimetry (DSC), and their films were too brittle to be analyzed by dynamic mechanical thermal analysis (DMA). $T_{\mathrm{g}}$ of polyamide $4 \mathrm{~b}$ was $339^{\circ} \mathrm{C}$ and that of $4 \mathrm{~d}$ was $370^{\circ} \mathrm{C}$, both high values. The temperatures at $5 \%$ weight loss $\left(T_{\mathrm{d}} \mathrm{s}\right)$ and weight residues at $600^{\circ} \mathrm{C}$ were observed by thermogravimetry (TG). $T_{\mathrm{d}} \mathrm{s}$ of polyamides 4 were $442-482^{\circ} \mathrm{C}$ and weight residues at $600^{\circ} \mathrm{C}$ were $57-68 \%$, which are high values. Compared with thermal properties between polyamides 2 and 4 , those of polyamides 4 were as high as those of the corresponding polyamides $2 . T_{\mathrm{g}} \mathrm{s}$ of $\mathbf{2 b}$ was $337^{\circ} \mathrm{C}$, that of $4 \mathrm{~b}$ was $339^{\circ} \mathrm{C}$, and $T_{\mathrm{g}} \mathrm{s}$ of $2 \mathrm{~d}$ and $4 \mathrm{~d}$ were $370^{\circ} \mathrm{C}$. $T_{\mathrm{d}} \mathrm{s}$ of polyamides 2 also showed values as high as those of corresponding polyamides 4 . These were due to the same

Table II. Solubility of polyamides ${ }^{\mathbf{a}}$

\begin{tabular}{ccccccccccc}
\hline Polymer & CHO & Py & $m$-Cre & DMAc & NMP & HMPA & DMF & DMSO & $\mathrm{H}_{2} \mathrm{SO}_{4}$ \\
\hline $\mathbf{a}$ & $( \pm)$ & $( \pm)$ & $( \pm)$ & + & $(+)$ & $(+)$ & $( \pm)$ & + & + \\
$\mathbf{2}^{\mathbf{3}}$ & $(+)$ & + & $(+)$ & + & + & $(+)$ & + & + & + \\
$\mathbf{c}$ & $( \pm)$ & $( \pm)$ & - & - & $(+)$ & $( \pm)$ & - & - & $(+)$ & + \\
$\mathbf{d}$ & $( \pm)$ & + & $( \pm)$ & + & + & $(+)$ & + & + & + & + \\
\hline $\mathbf{a}$ & - & - & - & - & $( \pm)^{\mathbf{b}}$ & - & - & & - & + \\
$\mathbf{4}$ & - & $(+)$ & - & + & + & \pm & + & + & + \\
$\mathbf{c}$ & $( \pm)$ & \pm & $( \pm)$ & $( \pm)$ & $( \pm)^{\mathbf{b}}$ & $( \pm)$ & \pm & \pm & + \\
$\mathbf{d}$ & $\mathrm{SW}$ & \pm & $\mathrm{SW}$ & + & + & $(+)$ & \pm & + & +
\end{tabular}

a Measured at a concentration of $0.020 \mathrm{~g} \mathrm{ml}^{-1}$.

CHO, cyclohexanone; Py, pyridine; $m$-Cre, $m$-cresol; DMAc, dimethylacetamide; NMP, 1-methyl-2-pyrrolidone; DMF, dimethylformamide; DMSO, dimethylsulfoxide; HMPA, hexamethylphosphoric triamide.

+ , soluble; \pm , partially soluble; - , insoluble; SW, swelling; ( ), on heating.

b It was soluble when lithium chloride was added at room temperature. 
Polymers Prepared from 2,5-Triptycenediamine

Table V. Solubility of polyimides ${ }^{\mathbf{a}}$

\begin{tabular}{cccccccccc}
\hline Polymer & CHO & Py & $m$-Cre & DMAc & NMP & HMPA & DMF & DMSO & $\mathrm{H}_{2} \mathrm{SO}_{4}$ \\
\hline $\mathbf{a}^{\prime}$ & - & - & - & $\mathrm{SW}$ & $( \pm)$ & - & $( \pm)$ & - & $(+)$ \\
$\mathbf{6}^{\mathbf{b}^{\prime}}$ & - & - & - & - & - & - & - & - & $(+)$ \\
$\mathbf{c}^{\prime}$ & - & - & - & $(\mathrm{SW})$ & - & - & $( \pm)$ & $(\mathrm{SW})$ & $( \pm)$ \\
$\mathbf{d}^{\prime}$ & - & - & - & + & $( \pm)$ & $( \pm)$ & + & + & + \\
\hline
\end{tabular}

${ }^{\mathrm{a}}$ Measured at $0.020 \mathrm{~g} \mathrm{ml}^{-1}$.

CHO, cyclohexanone; Py, pyridine; $m$-Cre, $m$-cresol; DMAc, dimethylacetamide; NMP, 1-methyl-2-pyrrolidone; DMF, dimethylformamide; DMSO, dimethylsulfoxide; HMPA, hexamethylphosphoric triamide.

+ , soluble; \pm , partially soluble; - , insoluble. SW, swelling; ( ), on heating.

good for aromatic polyimide, which was soluble in DMAc, DMF, DMSO, and conc. sulfuric acid.

The thermal properties of polyimides 6 are summarized in Table VI. $T_{\mathrm{g}} \mathrm{s}$ of polyimides were determined by DMA. $T_{\mathrm{g}} \mathrm{s}$ of polyimides 6 were observed in the $389-418^{\circ} \mathrm{C}$ range due to the rigidity and symmetry of the diamine component. The temperatures at $5 \%$ weight loss of polyimides 6 were up to $521^{\circ} \mathrm{C}$ and the weight residue at $600^{\circ} \mathrm{C}$ was above $82 \%$, and even at $800^{\circ} \mathrm{C}$ was above $64 \%$, which gave indication of highly thermally stable polymer. Especially, polyimide $\mathbf{6 d}^{\prime}$ had good solubility in several organic solvents and highly thermal properties $\left(T_{\mathrm{g}}=404^{\circ} \mathrm{C}, T_{\mathrm{d}}=521^{\circ} \mathrm{C}\right)$.

\section{EXPERIMENTAL}

9,10-Dihydro-9,10-o-benzenoanthracene1,4-diamine (2,5-triptycenediamine) 3: The diamine was synthesized from anthracene and p-quinone, as starting materials through five steps by the method ${ }^{4}$ of Barttlett et al. The total yield from starting materials was $27.4 \%$. $\mathrm{mp} 310^{\circ} \mathrm{C}$ (DTA) $\left(\right.$ lit. $^{4} 307^{\circ} \mathrm{C}$ ), light gray powder. IR (KBr) $3464,3384 \mathrm{~cm}^{-1}(\mathrm{~N}-\mathrm{H})$.

Anal. Calcd for $\mathrm{C}_{20} \mathrm{H}_{14} \mathrm{~N}_{2}$ (284.4): C, $84.48 \%$; H, 5.67\%; N, 9.85\%. Found : C, $84.72 \%$; H, $5.59 \%$; N, $9.75 \%$.

\section{Monomer}

4,4'-Sulfonyldibenzoic acid and 3,3',4,4'biphenylsulfonetetracarboxylic dianhydride
Table VI. Thermal properties of polyimides

\begin{tabular}{|c|c|c|c|c|}
\hline \multirow{2}{*}{ Polymer } & \multirow{2}{*}{$\frac{T_{\mathrm{g}}^{\mathrm{a}}}{{ }^{\circ} \mathrm{C}}$} & \multirow{2}{*}{$\frac{T_{\mathrm{d}}^{\mathrm{b}}}{{ }^{\circ} \mathrm{C}}$} & \multicolumn{2}{|c|}{ Weight residue $/ \%^{\mathrm{c}}$} \\
\hline & & & at $600^{\circ} \mathrm{C}$ & at $800^{\circ} \mathrm{C}$ \\
\hline $\mathbf{a}^{\prime}$ & - & 563 & 83 & 64 \\
\hline $6^{b^{\prime}}$ & 399 & 592 & 93 & 68 \\
\hline${ }^{\mathbf{b}} \mathbf{c}^{\prime}$ & 391 & 570 & 85 & 67 \\
\hline$d^{\prime}$ & 411 & 521 & 82 & 65 \\
\hline
\end{tabular}

a Measured by dynamic mechanical thermal analysis (DMA) (heating rate $1 \mathrm{~K} \mathrm{~min}^{-1}$ in nitrogen atmosphere at $0.025 \mathrm{~Hz}$ ).

b Temperature at $5 \%$ weight loss was determined by thermogravimetry (TG) (heating rate $10 \mathrm{~K} \mathrm{~min}^{-1}$ in nitrogen atmosphere).

c Determined by TG.

were obtained from New Japan Chemical Co., Ltd., and used as received. Aromatic dicarbonyl dichlorides were synthesized from the aromatic dicarboxylic acid with thionyl chloride and DMF. Terephthaloyl dichloride was recrystallized from dry $n$-hexane. Isophthaloyl dichloride was recrystallized from dry ligroin. 4,4'-Biphenyldicarbonyl chloride and 4,4'sulfonyldibenzoyl chloride were recrystallized from dry benzene. Pyromellitic dianhydride, 3,3'4,4'-benzophenonetetracarboxylic dianhydride, and 3,3',4,4'-biphenyltetracarboxylic dianhydride were obtained commercially, recrystallized from acetic anhydride, and sublimated under vacuum just before polymerization. 


\section{1,4-Dibenzamide-9,10-dihydro-9,10-o-benzeno- anthracene (Polyamide Model)}

In a $50-\mathrm{ml}$ four-necked flask equipped with a reflux condenser and a nitrogen gas inlet were placed $1.49 \mathrm{~g}$ of diamine $3,7.83 \mathrm{ml}$ of DMAc, $1.86 \mathrm{ml}$ of benzoyl chloride, and a magnetic stirrer bar. The mixture was cooled to $-18^{\circ} \mathrm{C}$ and stirred until all the ingredients were dissolved. Then, $5.92 \mathrm{ml}$ of propylene oxide were added. The reaction mixture was stirred for $1 \mathrm{~h}$. The mixture was stirred at room temperature for $2 \mathrm{~h}$ and then poured into $400 \mathrm{ml}$ of water. The precipitates were filtrated, washed with $380 \mathrm{ml}$ of $10 \%$ sodium carbonate solution and $500 \mathrm{ml}$ of water, and dried in vacuo. Crude products were recrystallized from acetone. Yield $91 \%$. mp $321-322^{\circ} \mathrm{C}$ (DTA). IR (KBr) $1654,1514 \mathrm{~cm}^{-1}$ (amide I, II).

Anal. Calcd for $\mathrm{C}_{34} \mathrm{H}_{24} \mathrm{~N}_{2} \mathrm{O}_{2}$ (492.6): C, $82.91 \%$; H, 4.91\%; N, 5.69\%. Found: C, $82.70 \%$; H, $4.72 \%$; N, $5.42 \%$.

\section{$N, N^{\prime}-(9,10-D i h y d r o-9,10-o-b e n z e n o a n t h r a c e n e-$}

1,4-diyl)-diphthalimide (Polyimide Model)

In a four-necked $10-\mathrm{ml}$ reaction tube equipped with a mechanical stirrer and nitrogen inlet with a calcium chloride tube were placed $0.568 \mathrm{~g}$ of diamine 3 and $3.0 \mathrm{ml}$ of NMP. After the mixture was cooled to $-15^{\circ} \mathrm{C}, 0.604 \mathrm{~g}$ of phthalic anhydride was added. It was stirred at that temperature for $1 \mathrm{~h}$ and then at room temperature for $4 \mathrm{~h}$. The resulting solution was spread on a glass plate and the solvent was removed at $60^{\circ} \mathrm{C}$ for $1.5 \mathrm{~h}$ and then at $70^{\circ} \mathrm{C}$ for $1 \mathrm{~h}$. The film thus obtained was dried in vacuo at $60^{\circ} \mathrm{C}$. Thermal cyclodehydration was performed at $150{ }^{\circ} \mathrm{C}$ for $2 \mathrm{~h}$ in a nitrogen atmosphere and then at $300^{\circ} \mathrm{C}$. Crude yield was $85.5 \%$. The products were recrystallized from cyclohexanone. Yield $40.2 \%$. mp $460^{\circ} \mathrm{C}$ (DTA, white powder). IR (KBr) $1720(\mathrm{C}=\mathrm{O}), 1372$ $(\mathrm{C}-\mathrm{N}) \mathrm{cm}^{-1}$.

Anal. Calcd for $\mathrm{C}_{36} \mathrm{H}_{20} \mathrm{~N}_{2} \mathrm{O}_{4}$ (544.5): C, $79.40 \% ; \mathrm{H}, 3.70 \% ; \mathrm{N}, 5.14 \%$. Found: C,
$79.18 \% ; \mathrm{H}, 3.56 \% ; \mathrm{N}, 4.94 \%$.

\section{Low-Temperature Solution Polycondensation of} Polyamide

A typical procedure is as follows. In a $10-\mathrm{ml}$ reaction tube equipped with a nitrogen gas inlet having a calcium chloride tube were placed $0.1287 \mathrm{~g}$ of lithium chloride, $0.2843 \mathrm{~g}$ of diamine 3 , and $1.80 \mathrm{ml}$ of NMP. The mixture was dissolved, cooled to $-18^{\circ} \mathrm{C}$, to which were added $0.3431 \mathrm{~g}$ of $4,4^{\prime}$-sulfonyldibenzoyl chloride and $0.70 \mathrm{ml}$ of propylene oxide. It was stirred at $-18^{\circ} \mathrm{C}$ for $1 \mathrm{~h}$, subsequently at $-10^{\circ} \mathrm{C}$ for $1 \mathrm{~h}$, and at room temperature for $5 \mathrm{~h}$. The reaction mixture was poured into aqueous methanol $\left(\mathrm{MeOH}: \mathrm{H}_{2} \mathrm{O}=1: 1\right.$ in volume). The precipitates were collected with a glass filter $(3 \mathrm{G})$ and then dried in reduced pressure at $70^{\circ} \mathrm{C}$. Yield $96.5 \% . \quad \eta_{\text {inh }}=0.84$ $\mathrm{dlg}^{-1}\left(0.5 \mathrm{~g} \mathrm{dl}^{-1}\right.$ conc. $\mathrm{H}_{2} \mathrm{SO}_{4}$ at $\left.30^{\circ} \mathrm{C}\right)$. IR (KBr) $1656,1514 \mathrm{~cm}^{-1}$ (amide I, II).

Anal. Calcd for $\left(\mathrm{C}_{34} \mathrm{H}_{22} \mathrm{~N}_{2} \mathrm{O}_{4} \mathrm{~S}\right)_{n}$ (554.6) C, $73.63 \%$; H, $4.00 \%$; N, 5.05\%. Found: C, $71.62 \% ; \mathrm{H}, 3.98 \% ; \mathrm{N}, 4.86 \%$. Other polyamides were synthesized by similar procedure.

\section{Ring-Opening Polyaddition and Cyclodehydra- tion of Polyimide 6}

A typical procedure is as follows. In a fournecked $10-\mathrm{ml}$ reaction tube equipped with a mechanical stirrer and a nitrogen inlet having a calcium chloride tube, were placed $0.2844 \mathrm{~g}$ of diamine 3 and $1.0 \mathrm{ml}$ of NMP. The mixture was chilled to $-15^{\circ} \mathrm{C}$, and to which were added $0.2180 \mathrm{~g}$ of pyromellitic anhydride and $1.0 \mathrm{ml}$ of NMP. It was stirred at room temperature for $4 \mathrm{~h}$ and then was allowed to stand over night. A $0.50-\mathrm{ml}$ portion of the reaction mixture was removed for viscosity measurement. The remaining mixture was spread on a glass plate and the solvent was removed at $70^{\circ} \mathrm{C}$. The obtained film was dried under reduced pressure. Thermal cyclodehydration of the polyamic acid 7 was performed by heating at $180^{\circ} \mathrm{C}$ for $2 \mathrm{~h}$ and then at $350^{\circ} \mathrm{C}$ for $1 \mathrm{~h}$. As soon as heating was over, the product was 
taken out of an electric furnace and cooled to room temperature. The inherent viscosity of the polyamic acid was $0.47 \mathrm{dlg}^{-1}\left(0.5 \mathrm{~g} \mathrm{dl}^{-1}\right.$ NMP at $30^{\circ} \mathrm{C}$ ).

Anal. Calcd for $\left(\mathrm{C}_{30} \mathrm{H}_{14} \mathrm{~N}_{2} \mathrm{O}_{4}\right)_{n}(466.4)_{n}$ : C, $77.25 \%$; H, 3.03\%; N, 6.01\%. Found: C, $74.22 \%$; H, 3.33\%; N, 5.45\%. Other polyimides were synthesized by similar procedure.

\section{MEASUREMENTS}

$T_{\mathrm{g}} \mathrm{s}$ were obtained by DSC (Rigakudenki Thermal Analysis 8055D1), and determined on dynamic mechanical thermal analysis (DMA) (Mac Science TMA 4000). DMA measurement was made at a frequency of $0.025 \mathrm{~Hz}$ at a heating rate of $1 \mathrm{~K} \mathrm{~min}^{-1}$. The sample was about $0.02 \mathrm{~mm}$ thick, $5 \mathrm{~mm}$ wide, and $20 \mathrm{~mm}$ gauge length. $T_{\mathrm{d}} \mathrm{s}$ and weight residues were obtained by TG-DTA (Mac Science TG-DTA 2000). IR spectra were recorded on a Hitachi 270-30 spectrophotometer $(\mathrm{KBr}$ tablet).
Acknowledgments. We thank the Chemical Analysis Center, Chiba University, for carrying out the elemental analyses. We are indebted to New Japan Chemical Co., Ltd., for providing the $4,4^{\prime}$-sulfonyldibenzoic acid and $3,3^{\prime}, 4,4^{\prime}$-biphenylsulfonetetracarboxylic dianhydride.

\section{REFERENCES}

1. P. E. Cassidy, "Thermally Stable Polymers," Dekker, New York, N.Y., 1980.

2. Y. Kasashima, T. Kaneda, G. Saito, F. Akutsu, K. Naruchi, and M. Miura, Macromol. Chem. Phys., in press.

3. A. K. Mikitaev, V. V. Korshak, Kh. Kh. Gurdaliev, and V. N. Pryadko, Vysokomol. Soedin., Ser. B, 25(11), 845 (1983) [Chem. Abstr., 100, 86198p (1984)].

4. P. D. Bartlett and F. M. Logullo, J. Am. Chem. Soc., 85, 1549 (1963).

5. P. W. Morgan, "Condensation Polymers by Interfacial and Solution Methods," Interscience, New York, N.Y., 1965.

6. C. E. Sroog, J. Polym. Sci., Makromol. Rev., 11, 161 (1976). 